\title{
Accuracy Analysis of Iliac Screw Using Freehand Tech- nique in Spinal Surgery : Relation between Screw Breach and Revision Surgery
}

\author{
Subum Lee, ${ }^{1, *}$ Sang Ku Jung, ${ }^{2, *}$ Sam G. Keshen, ${ }^{3}$ Stephen J. Lewis, ${ }^{3}$ Jin Hoon Park \\ Department of Neurological Surgery, ${ }^{\prime}$ Asan Medical Center, University of Ulsan College of Medicine, Seoul, Korea \\ Department of Emergency Medicine, ${ }^{2}$ Gangneung Asan Hospital, University of Ulsan College of Medicine, Gangneung, Korea \\ Division of Orthopaedic Surgery, University Health Network, Toronto Western Hospital, Toronto, Canada
}

Objective : To analyze the accuracy of iliac screws using freehand technique performed by the same surgeon. We also analyzed how the breach of iliac screws was related to the clinical symptoms resulting in revision surgery.

Methods : From January 2009 to November 2015, 100 patients (193 iliac screws) were analyzed using postoperative computed tomography scans. The breaches were classified based on the superior, inferior, lateral, and medial iliac wall violation by the screw. According to the length of screw extrusion, the classification grades were as follows : grade 1, screw extrusion $<1 \mathrm{~cm}$; grade II, $1 \mathrm{~cm} \leq$ screw extrusion $<2 \mathrm{~cm}$; grade III, $2 \mathrm{~cm} \leq$ screw extrusion $<3 \mathrm{~cm}$; and grade IV, $3 \mathrm{~cm} \leq$ screw extrusion. We also reviewed the revision surgery associated with iliac screw misplacement.

Results : Of the 193 inserted screws, 169 were correctly located and 24 were misplaced screws. There were eight grade I, six grade II, six grade III, and four grade IV screw breaches, and 11, 8, 2, and 3 screws violated the medial, lateral, superior, and inferior walls, respectively. Four revision surgeries were performed for the grade III or IV iliac screw breaches in the lateral or inferior direction with respect to its related symptoms.

Conclusion : In iliac screw placement, $12.4 \%$ breaches developed. Although most breaches were not problematic, symptomatic violations (2.1\%) could result in revision surgery. Notably, the surgeon should keep in mind that lateral or inferior wall breaches longer than $2 \mathrm{~cm}$ can be risky and should be avoided.

Key Words : Sacropelvic fixation · lliac screw · Breach · Accuracy · Freehand technique.

- Received : April 9, 2019 •Revised : June 20, 2019 •Accepted : August 12, 2019

- Address for reprints : Stephen J. Lewis

Division of Orthopaedic Surgery, Toronto Western Hospital, University Health Network, 399 Bathurst Street, East Wing, Toronto M5T 2S8, Canada

Tel : +1-416-603-5851, Fax : +1-416-603-3437, E-mail : stephen.lewis@uhn.ca, ORCID : https://orcid.org/0000-0002-9173-8443

\section{Jin Hoon Park}

Department of Neurological Surgery, Asan Medical Center, University of Ulsan College of Medicine, 88 Olimpic-ro 43-gil, Songpa-gu, Seoul 05505, Korea Tel : +82-2-3010-3550, Fax : +82-2-476-6738, E-mail : jhpark@amc.seoul.kr, ORCID : https://orcid.org/0000-0002-0903-3146

*Subum Lee and Sang Ku Jung contributed equally to this work.

This is an Open Access article distributed under the terms of the Creative Commons Attribution Non-Commercial License (http://creativecommons.org/licenses/by-nc/4.0) which permits unrestricted non-commercial use, distribution, and reproduction in any medium, provided the original work is properly cited. 


\section{INTRODUCTION}

The use of iliac screws to avoid pseudoarthrosis or fixation failure at the lumbosacral junction has been popularized. Clinical indications of sacropelvic fixation include long fusions extending to the sacrum, flat back deformity requiring corrective osteotomy, correction of pelvic obliquity, highgrade spondylolisthesis, sacrectomy, sacral fractures with spinopelvic dissociation, and substantial osteoporosis in the setting of lumbosacral fusion. Regardless of the specific clinical abnormality, each of these indications requires sacropelvic instrumentation to provide a secure distal foundation that resists the strong flexion movements and cantilever forces present at the lumbosacral junction, thus preventing fixation failures, pseudoarthrosis, and progressive deformities ${ }^{7,8)}$.

Although the freehand technique of screw placement at the cervical, thoracic, and lumbar spinal levels and its accuracy have been introduced and popularized, those of pelvic instrumentation were absent despite its popular use $\mathrm{e}^{10,14,15)}$.

Here, the accuracy of iliac screws using freehand technique performed by a 10-year experienced single spinal deformity surgeon was analyzed. Additionally, how the breach of iliac screw was related to the clinical symptoms resulting in revision surgery was evaluated.

\section{MATERIALS AND METHODS}

This study was approved by the Institutional Review Board of Toronto Western Hospital. From January 2009 to November 2015, 148 consecutive adult patients underwent pelvic fixation using the freehand technique iliac screw placement at the posterior spinal inferior spine (PSIS) by the same surgeon. Postoperative computed tomography (CT) scans during follow up were possible for 100 of these patients, and they were included in this study. There were 27 male and 73 female patients with a mean age of 63.5 years (range, 20-85).

The initial diagnoses were degenerative scoliosis with or without sagittal imbalance $(n=66)$, distal level degeneration, flat back, or curve progression after adolescent idiopathic scoliosis surgery $(n=21)$, congenital scoliosis $(n=1)$, high-grade spondylolisthesis $(n=4)$, tuberculosis kyphosis $(n=1)$, trauma $(n=2)$, and tumor $(n=5)$. Basic characteristics of patients are shown in Table 1.
Table 1. Basic characteristics of patients

\begin{tabular}{lc}
\hline & Value $(\mathbf{n}=100)$ \\
\hline Mean age (range) & $63.5(20-85)$ \\
Sex (male/female) & $27 / 73$ \\
Unilateral/bilateral iliac screw & $7 / 93$ \\
Disease & \\
DS & 66 \\
Post AIS surgery & 21 \\
CS & 1 \\
High grade spondylolisthesis & 4 \\
TB kyphosis & 1 \\
Trauma & 2 \\
Tumor & 5 \\
\hline
\end{tabular}

DS : degenerative scoliosis with or without sagittal imbalance, post AIS surgery : distal level degeneration, flat back, or curve progression after adolescent idiopathic scoliosis surgery, CS : congenital scoliosis, TB : tuberculosis

\section{Surgical technique}

The bone around PSIS was removed after its exposure with an osteotome and Rongeur forceps to avoid screw protuberance. The screw entry point was located at the center of the PSIS, directly beneath the most prominent region. The pedicle probe was inserted by the gear-shift method (Fig. 1A and B). In other words, if the pedicle probe did not move forward by touching the inner cortical bone, it was turned by $180^{\circ}$ and then made to proceed in the true cancellous channel. This path finding by the gear-shift method was repeated to create a screw trajectory. A pelvic lateral wall slope was used for creating a lateral angle of the screw trajectory (Fig. 1C), and the greater trochanter was used for the inferior angle of screw trajectory in the freehand technique. The inferior angle was set on the basis of the greater trochanter, which is the most obvious and easily palpable anatomical marker for screw trajectory. The actual screw trajectory should be approximately 15$20^{\circ}$ above the greater trochanter (Fig. 1A and B).

After inserting the probe approximately $7-8 \mathrm{~cm}$ deep, the pedicle probe was removed and the five bony walls (medial, lateral, superior, inferior, and depth of bottom) were confirmed through ball-tip probing. The final step was tapping and screw placement. A screw of 70-80 mm length and 8.5$9.5 \mathrm{~mm}$ diameter was used according to the intraoperative measurement using a ball-tip probe. Lateral connector was used for connection of main rod and iliac screw. 

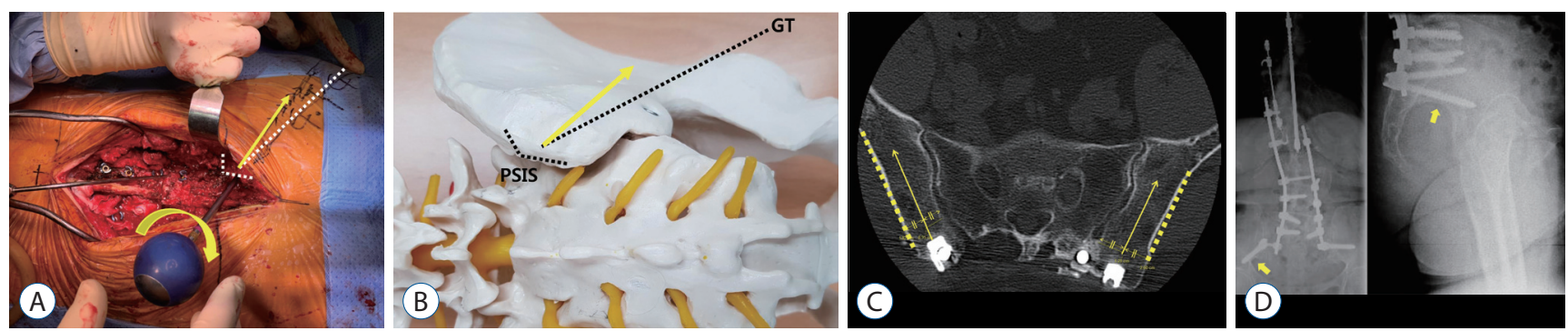

Fig. 1. A : Intraoperative photograph showing a screw trajectory with a pedicle probe after removal of the PSIS. First, the GT is palpated to identify it (white dotted line) and then it is used as a marker to advance the pedicle probe $15^{\circ}$ above (yellow arrows). B : A model showing the screw entry point (center of the PSIS) and inferior angle ( $15^{\circ}$ above the GT, yellow arrow). C : Postoperative computed tomography image showing that the screw entry point is located in the center of the PSIS (yellow arrows) and the pelvic lateral wall slope used for creating a lateral angle of the screw trajectory (yellow dotted lines). D : After screw insertion, portable anterior-posterior (AP) and lateral radiographs were obtained before the closure. In these images, the screw location was considered acceptable if it was above the sciatic notch (yellow arrows). PSIS : posterior superior iliac spine, GT : greater trochanter.
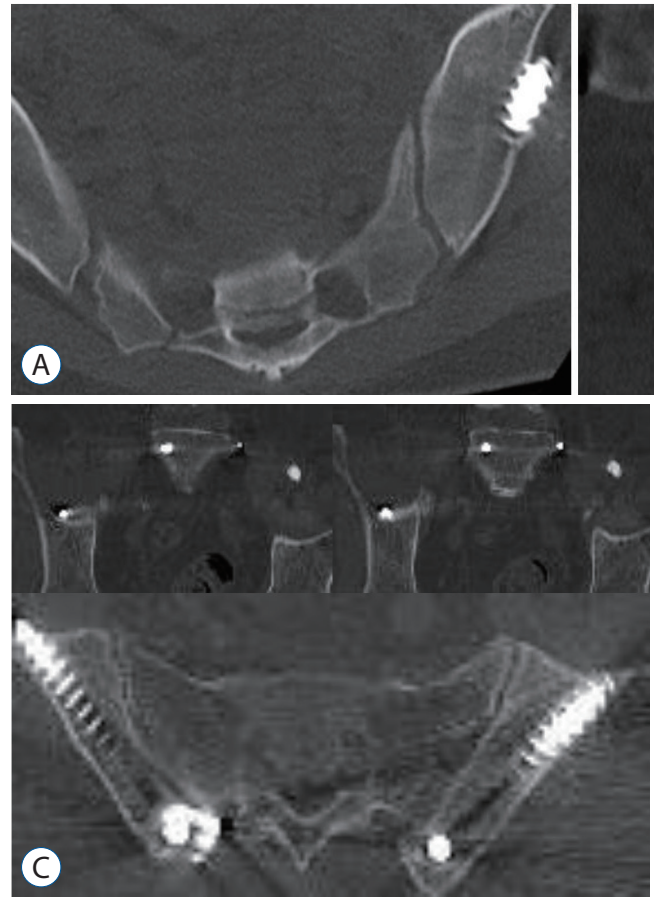
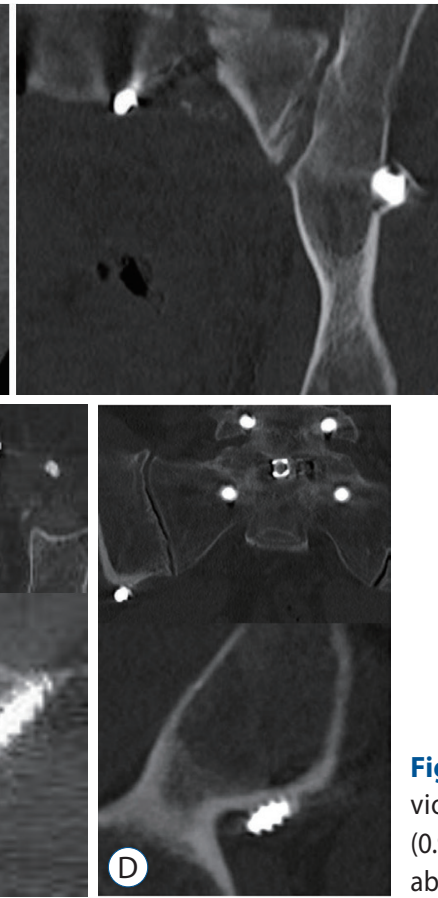

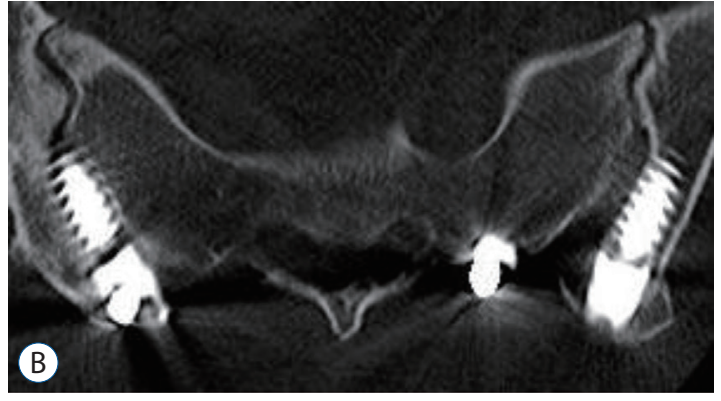

B
Fig. 2. A : Lateral wall violation, grade III $(2.44 \mathrm{~cm})$. B : Medial wall violation, grade III $(2.38 \mathrm{~cm})$. C : Superior wall violation, grade I $(0.97 \mathrm{~cm})$. D : Inferior wall violation, grade III $(2.21 \mathrm{~cm})$; none of the above cases needed revision surgery.
After screw insertion, portable anterior-posterior (AP) and lateral radiographs were obtained before the closure. In these images, the screw location was considered acceptable if it was above the sciatic notch (Fig. 1D). The screw was removed or repositioned if it passed through a position lower than the sciatic notch.

\section{Accuracy analysis of iliac screw}

The mean assessment time of 1-mm thin CT section was 1.7 years (range, 1 month to 5.5 years). We analyzed iliac wall violation using coronal, sagittal, and axial CT scans, and were classified as superior, inferior, lateral, and medial iliac wall violation of the screw (Fig. 2). Unilateral iliac screw placement was performed in seven patients, and their contralateral sides were skipped. Bilateral iliac screw placement was performed in 93 patients. Hence, 193 iliac screws using postoperative CT scans were analyzed in this study. The longest measurement of the extruded screw tip from the violated iliac wall in the sagittal, coronal, and axial CT scans was recorded for the violated screw. According to the length of screw extrusion, the classification grades were as follows : screw extrusion $<1 \mathrm{~cm}$, grade I; $1 \mathrm{~cm} \leq$ screw extrusion $<2 \mathrm{~cm}$, grade II; $2 \mathrm{~cm} \leq$ screw extru- 
Table 2. Demographic features of corrected and misplaced screws

\begin{tabular}{|c|c|c|c|}
\hline & Correctly located screws $(n=169)$ & Misplaced screws $(n=24)$ & $p$-value \\
\hline Mean age & $64.5 \pm 13.3$ & $55.2 \pm 15.3$ & $0.017^{*}$ \\
\hline Sex (male/female) & $46 / 123$ & $6 / 18$ & 1.000 \\
\hline Right/left side & $81 / 88$ & $14 / 10$ & 0.388 \\
\hline Disease & & & $0.004^{*}$ \\
\hline DS & 116 & 12 & \\
\hline Post AIS surgery & 33 & 8 & \\
\hline CS & 2 & 0 & \\
\hline High grade spondylolisthesis & 6 & 1 & \\
\hline TB kyphosis & 0 & 2 & \\
\hline Trauma & 3 & 1 & \\
\hline Tumor & 9 & 0 & \\
\hline
\end{tabular}

DS : degenerative scoliosis with or without sagittal imbalance, post AIS surgery : distal level degeneration, flat back, or curve progression after adolescent idiopathic scoliosis surgery, CS : congenital scoliosis, TB : tuberculosis

sion $<3 \mathrm{~cm}$, grade III; $3 \mathrm{~cm} \leq$ screw extrusion, grade IV. The revision surgery associated with iliac screw misplacement was also reviewed.

\section{Radiographic loosening of screws and L5-S1 fu- sion rate}

We analyzed screw loosening and lumbosacral junction fusion rate during the follow-up period (mean, 1.7 years) using postoperative CT scans. A $>1-\mathrm{mm}$-wide radiolucent line around the implant on CT scans is considered evidence of screw loosening ${ }^{17,24,25)}$. L5-S1 bone fusion was evaluated on the basis of evidence of bridging trabecular bone ${ }^{24)}$. Revision surgery associated with iliac screw loosening and L5-S1 fusion failure was reviewed.

\section{Statistical analysis}

The statistical program SPSS version 20 (SPSS Inc., Chicago, IL, USA) was used to perform all statistical analyses. The chisquared test, Fisher's exact test, student's t-test, and MannWhitney $\mathrm{U}$ test were used for statistical analysis. A $p$-value $<0.05$ was considered statistically significant.

\section{RESULTS}

Among the 100 patients, five patients complained of discomfort associated with the iliac screw head irritation in the buttock, thus resulting in four revision surgeries to remove the iliac screw.

Among 193 inserted screws, 169 were correctly located and 24 were misplaced. There was a significant difference in the mean age and disease between the correct and misplaced iliac screws ( $p=0.017$ and 0.004 , respectively; Table 2). There were eight grade I, six grade II, six grade III, and four grade IV screws breaches, and 11, 8, 2, and 3 screw breaches in medial, lateral, superior, and inferior walls, respectively. Four revision surgeries were performed for grade III or IV iliac screw breaches and their related symptoms. The revision surgery patients comprised of two patients with 2.89 and $3.12 \mathrm{~cm}$ lateral wall violation (grade III and IV) and two with 2.32 and 4.20 $\mathrm{cm}$ inferior wall breaches (grade III and IV; Table 3, Fig. 3). Lateral wall perforation and inferior wall perforation symptoms included gluteal muscle pain and sciatic nerve compression, respectively. Revision surgeries for the patients with two lateral and one inferior wall breaches were performed after 1 year because the patients' complaints were mild and observational follow-up was possible. However, revision surgery in a patient with a $4.20-\mathrm{cm}$ inferior wall violation was necessary in the immediate postoperative period (7 days after surgery) because the patient complained of severe radiating leg pain caused by sciatic nerve compression by the iliac screw (Figs. 3D and 4).

Of the 193 screws, 15 (7.8\%) in 11 patients showed loosening on CT images. Four patients with a loosened iliac screw underwent revision surgery for screw repositioning due to lumbosacral junction pseudoarthrosis. Among the 15 screws, only 
one laterally misplaced screw was included.

Finally, nine screws (due to screw breaches in four and screw loosening in five) were repositioned under revision surgery during the follow-up period, and none of the nine repositioned screws showed a wall violation or loosening.

\section{DISCUSSION}

Despite substantial biomechanical forces at the lumbosacral junction, poor bone quality, and complex regional anatomy has been the cause of high rates of instrumentation failure or non-union in this area. This big challenge led the spine surgeons to use spinopelvic fixation that provided a powerful resistance against cantilever forces and flexion movement at the lumbosacral junction ${ }^{7,8)}$. The clinical indications of this technique included five or more level fusions extending to the sacrum, flat back deformity requiring corrective osteotomy, correction of pelvic obliquity, high-grade spondylolisthesis, sacrectomy, sacral fractures with spinopelvic dissociation, and substantial osteoporosis in the setting of lumbosacral fu$\operatorname{sion}^{2,7-9,16,20,21,23)}$.

Table 3. The characteristics of breached iliac screw

\begin{tabular}{|c|c|c|c|c|c|c|}
\hline & Grade I & Grade II & Grade III & Grade IV & Total violation & $\begin{array}{l}\text { Symptomatic revision related with } \\
\text { misplaced iliac screw }(n=4)\end{array}$ \\
\hline \multicolumn{7}{|l|}{ Wall violation } \\
\hline Medial wall & 3 & 4 & 2 & 2 & 11 & 0 \\
\hline Lateral wall & 3 & 2 & 2 & 1 & 8 & 2 (grade III and grade IV) \\
\hline Superior wall & 2 & 0 & 0 & 0 & 2 & 0 \\
\hline Inferior wall & 0 & 0 & 2 & 1 & 3 & 2 (grade III and IV) \\
\hline Total violation & 8 & 6 & 6 & 4 & 24 & \\
\hline
\end{tabular}

Grade $\mathrm{I}<1 \mathrm{~cm} ; 1 \mathrm{~cm} \leq$ grade $\|<2 \mathrm{~cm} ; 2 \mathrm{~cm} \leq$ grade $\mathrm{II}<3 \mathrm{~cm} ; 3 \mathrm{~cm} \leq$ grade IV
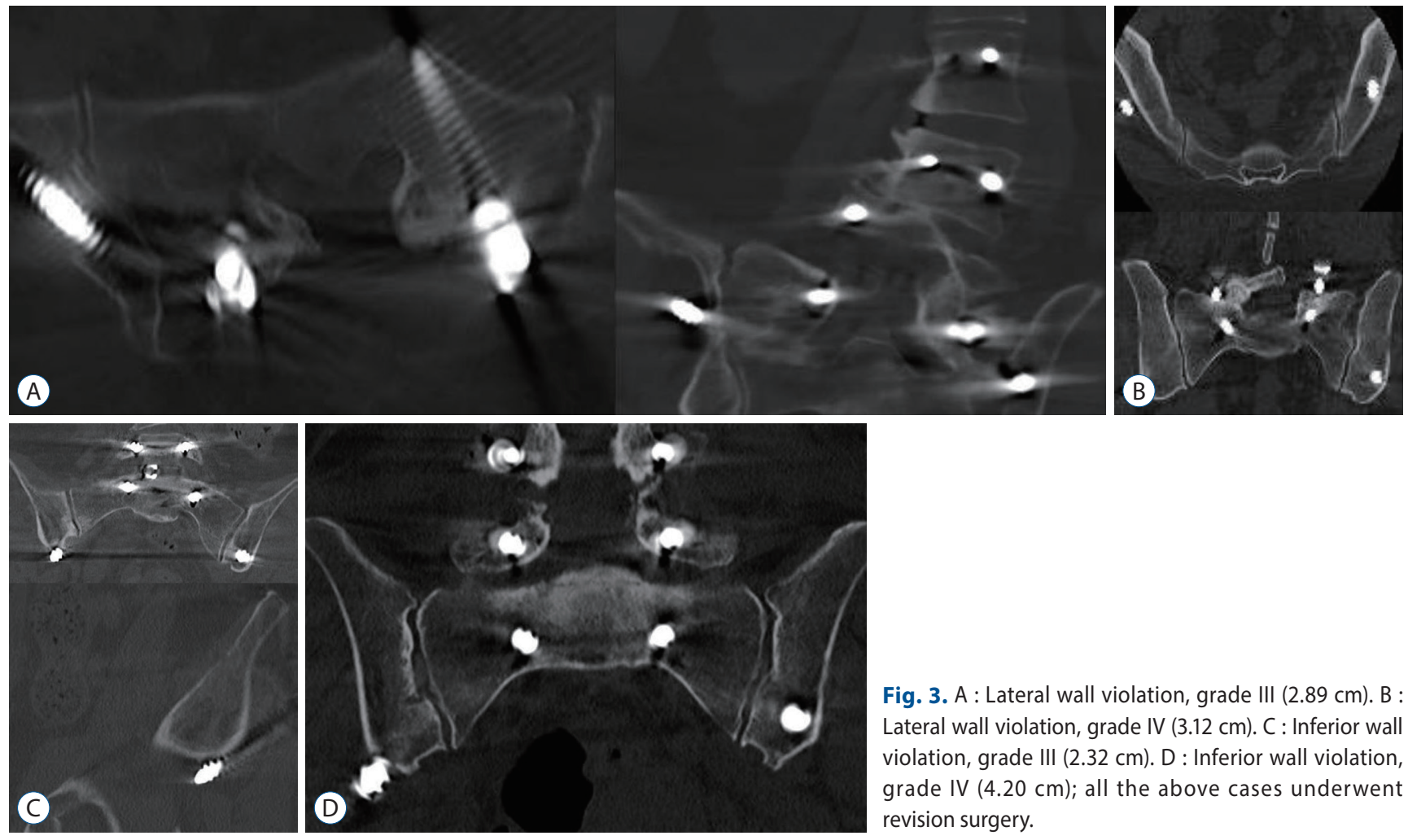

Fig. 3. A : Lateral wall violation, grade III $(2.89 \mathrm{~cm})$. B : Lateral wall violation, grade IV $(3.12 \mathrm{~cm}) . C$ : Inferior wall violation, grade III $(2.32 \mathrm{~cm})$. D : Inferior wall violation, grade IV $(4.20 \mathrm{~cm})$; all the above cases underwent revision surgery. 
In modern spinal surgery, technological evolutions have led to a decrease in surgical complications. Intraoperative imaging tools such as fluoroscopy or navigation system can be used in the iliac screw placement ${ }^{18,19)}$. Despite the improvement in accuracy offered by these technologies, their cost could be prohibitive in many spinal surgery centers. Moreover, these technologies may be associated with an increased risk of radiation exposure, increased operative time, and cumbersome additional hardware in the operating theatre. It has also been suggested that surgeons relying on these technologies may lose surgical skill and experience with respect to spinal instrumentation placement. The accuracy of freehand screw placement has been sufficiently reported and its clinical application is popular in spinal surgery ${ }^{5,10,14,15)}$. Furthermore, many spinal surgeons agree that it is difficult to use cumbersome equipment during long level or anatomically distorted deformity surgeries. However, a learning curve is necessary to use freehand technique with high accuracy ${ }^{12,14)}$. Until now, there was no accuracy analysis of freehand technique in iliac screw placement. The present study showed that $12.4 \%$ (24/193) iliac screw breaches could develop even with a 10-year experienced spinal surgeon, and especially occurred in the younger patients and post AIS surgery. We believe that this might be associated with revision surgery after AIS surgery in the relatively younger patients and could affect the high misplaced rates ${ }^{6}$.

Discomfort related to prominence of the screw in the skin resulted in screw removal, and this was one of the known

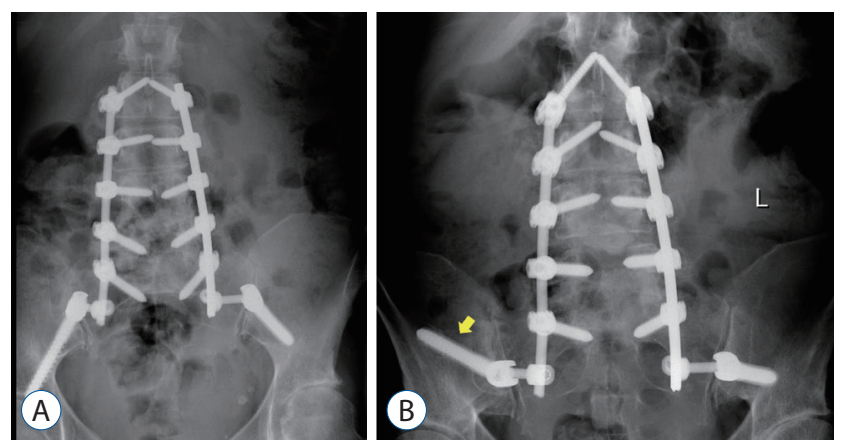

Fig. 4. Anterior-posterior radiographs of the spine in a 63-year-old woman with degenerative scoliosis. A : After the first surgery, both iliac screws were located above the sciatic notch on the image. However, the patient had severe pain in his right lower limb, and there was a grade IV screw breach on the right side; $4.20 \mathrm{~cm}$ inferior wall violation (Fig. 3D). B : Thus, we performed revisional surgery to replace the iliac screw toward a superior direction through another trajectory (yellow arrow). complications with iliac screw placement ${ }^{7,11,13,22}$. However, the reported revision surgery rate to remove the iliac screw due to patient discomfort was quite different. The revision rate in this study was $2.1 \%$ (4/193 screws). Besides the popularly known discomfort related to screw head irritation, there was no report of violated screw tips causing postoperative discomfort until now.

Symptomatic screw violation occurred in the lateral and inferior directions. The inferior wall violation by the screw could directly compress the sciatic nerve because the superior gluteal neurovascular bundle exists in the pelvis at the superior aspect of the greater sciatic notch ${ }^{4}$. When this type of violation occurs, the patient complains of radiating pain spreading to the buttock and lower part of the leg, accompanied by a claudication type of back pain and tenderness of the greater sciatic notch. Although, grades I or II violations did not seem to induce any symptoms, grade III violation in the lateral or inferior walls could cause postoperative pain associated with direct irritation of the gluteal muscle or sciatic nerve. Anatomically, superior wall violation should be rare and a smaller length of screw tip could penetrate it as seen in our data. Furthermore, medial wall violation may not produce any postoperative symptoms. However, we believe that biomechanical purchase power would be weak without full-length bone and screw engagement (Table 3, Fig. 2B).

The total number of screws was 193 (period 1, 48; period 2, 48; period 3, 48; and period 4, 49). Twenty-four screw violations occurred, including four (8.33\%) in period 1, 10 (20.83\%) in period 2, four ( $8.33 \%)$ in period 3, and six $(12.24 \%)$ in period 4 . The overall violation rate in the entire study period was

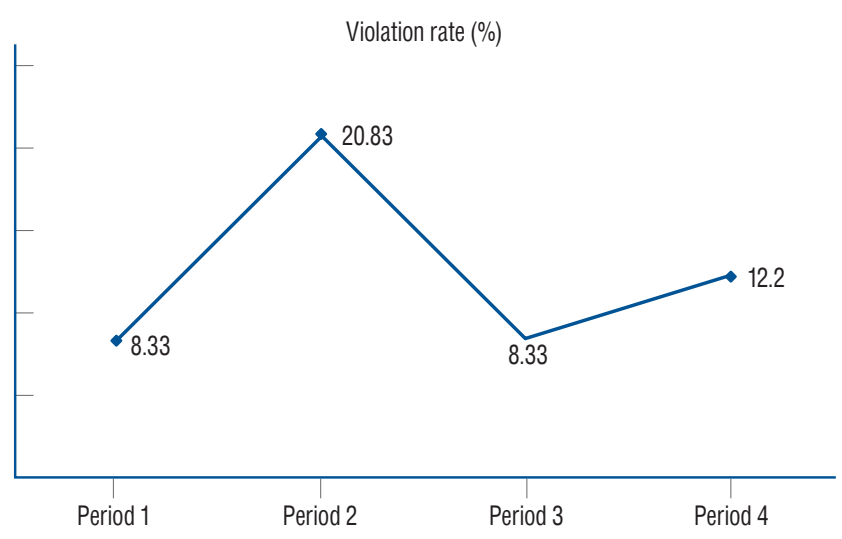

Fig. 5. The learning curve of iliac screw placement using the freehand technique (the violation rate is shown in the graph for each period). 
12.4\%. Our learning curve of the freehand technique for iliac screw placement showed that the violation rates reached a plateau at approximately $8-12 \%$ (Fig. 5). Although the overall misplacement rate reached $12.4 \%$, symptomatic pelvic wall violation was rare at $2.1 \%$ (4/193 screws). The surgeons should keep in mind that inferior wall or lateral wall perforation of iliac screw leads to postoperative pain that could require revision surgery.

Screw loosening, represented as a radiolucent area around the screw, indicates loss of screw fixation and potential progression to pseudarthrosis ${ }^{1,17)}$. The prevalence of iliac screw loosening after long spinal fusion is known to be particularly high $(7.5-52 \%)^{3,11,22)}$. In this study, the iliac screw loosening incidence rate (15/193 screws, $7.8 \%$ ) was similar to that of a previous report. Revision surgery is known to be a risk factor of lumbosacral fixation failure ${ }^{3)}$. In our results, no loosening occurred in the nine repositioned screws. Banno et al. ${ }^{1)}$ reported that the loosening group had a significantly higher rate of misplacement than the non-loosening group (54.5\% vs. $16.0 \%$ ). However, in our results, only one lateral wall violation occurred in 15 loosened screws, and no loosening occurred in the other misplaced screws.

For this study, the surgeon who performed all operations had more than 10 years of experience with spinal deformity surgery, thus, we do not believe that our breaches depended on inexperience.

\section{CONCLUSION}

In the iliac screw placement during spinal surgery using the freehand technique performed by an experienced spinal deformity surgeon, $12.4 \%$ breaches developed. Although majority breaches were not problematic, the symptomatic violation $(2.1 \%)$ could result in revision surgery. The surgeon should keep in mind that lateral or inferior wall breaches longer than $2 \mathrm{~cm}$ could be risky and should be avoided.

\section{CONFLICTS OF INTEREST}

No potential conflict of interest relevant to this article was reported.

\section{INFORMED CONSENT}

This type of study does not require informed consent.

\section{AUTHOR CONTRIBUTIONS}

\author{
Conceptualization : JHP \\ Data curation : JHP \\ Formal analysis : SKJ \\ Methodology : SJL \\ Project administration : SJL \\ Visualization : SGK \\ Writing - original draft : SL \\ Writing - review \& editing : SKJ, JHP
}

\section{ORCID}

$\begin{array}{ll}\text { Subum Lee } & \text { https://orcid.org/0000-0003-4732-8137 } \\ \text { Sang Ku Jung } & \text { https://orcid.org/0000-0002-9606-0440 } \\ \text { Sam G. Keshen } & \text { https://orcid.org/0000-0002-8266-1675 } \\ \text { Stephen J. Lewis } & \text { https://orcid.org/0000-0002-9173-8443 } \\ \text { Jin Hoon Park } & \text { https://orcid.org/0000-0002-0903-3146 }\end{array}$

\section{References}

1. Banno T, Hasegawa T, Yamato Y, Kobayashi S, Togawa D, Oe S, et al. : Prevalence and risk factors of iliac screw loosening after adult spinal deformity surgery. Spine (Phila Pa 1976) 42 : E1024-E1030, 2017

2. Bridwell $K H$, Lewis SJ, Lenke $L G$, Baldus $C$, Blanke $K$ : Pedicle subtraction osteotomy for the treatment of fixed sagittal imbalance. J Bone Joint Surg Am 85 : 454-463, 2003

3. Cho W, Mason JR, Smith JS, Shimer AL, Wilson AS, Shaffrey $\mathrm{Cl}$, et al. : Failure of lumbopelvic fixation after long construct fusions in patients with adult spinal deformity: clinical and radiographic risk factors: clinical article. J Neurosurg Spine 19 : 445-453, 2013

4. DeWald RL, Arlet V, Carl AL, Obrien MF : Spinal deformities: the comprehensive text. Stuttgart: Georg Thieme Verlag, 2003, pp11-12

5. Fridley J, Fahim D, Navarro J, Wolinsky JP, Omeis I : Free-hand placement of iliac screws for spinopelvic fixation based on anatomical landmarks: technical note. Int J Spine Surg 8 : 3, 2014

6. Hsieh JC, Drazin D, Firempong AO, Pashman R, Johnson JP, Kim TT : ACcuracy of intraoperative computed tomography image-guided surgery in placing pedicle and pelvic screws for primary versus revision spine 
surgery. Neurosurg Focus 36 : E2, 2014

7. Jain A, Hassanzadeh $H$, Strike SA, Menga EN, Sponseller PD, Kebaish $\mathrm{KM}$ : Pelvic fixation in adult and pediatric spine surgery: historical perspective, indications, and techniques: AAOS exhibit selection. J Bone Joint Surg Am 97 : 1521-1528, 2015

8. Kebaish KM : Sacropelvic fixation: techniques and complications. Spine (Phila Pa 1976) 35 : 2245-2251, 2010

9. Kim YJ, Bridwell KH, Lenke LG, Cheh G, Baldus C : Results of lumbar pedicle subtraction osteotomies for fixed sagittal imbalance: a minimum 5-year follow-up study. Spine (Phila Pa 1976) 32 : 2189-2197, 2007

10. Kim YJ, Lenke LG, Bridwell KH, Cho YS, Riew KD : Free hand pedicle screw placement in the thoracic spine: is it safe? Spine (Phila Pa 1976) 29 : 333-342; discussion 342, 2004

11. Kuklo TR, Bridwell KH, Lewis SJ, Baldus C, Blanke K, Iffrig TM, et al. : Minimum 2-year analysis of sacropelvic fixation and L5-S1 fusion using S1 and iliac screws. Spine (Phila Pa 1976) 26 : 1976-1983, 2001

12. Lee CH, Hyun SJ, Kim YJ, Kim KJ, Jahng TA, Kim HJ : Accuracy of free hand pedicle screw installation in the thoracic and lumbar spine by a young surgeon: an analysis of the first consecutive 306 screws using computed tomography. Asian Spine J 8 : 237-243, 2014

13. O'Shaughnessy BA, Lenke LG, Bridwell KH, Cho W, Zebala LP, Chang MS, et al. : Should symptomatic iliac screws be electively removed in adult spinal deformity patients fused to the sacrum? Spine (Phila Pa 1976) 37 : 1175-1181, 2012

14. Park JH, Jeon SR, Roh SW, Kim JH, Rhim SC : The safety and accuracy of freehand pedicle screw placement in the subaxial cervical spine: a series of 45 consecutive patients. Spine (Phila Pa 1976) 39 : 280-285, 2014

15. Parker SL, McGirt MJ, Farber SH, Amin AG, Rick AM, Suk I, et al. : Accuracy of free-hand pedicle screws in the thoracic and lumbar spine: analysis of 6816 consecutive screws. Neurosurgery 68 : 170-178; discussion 178, 2011
16. Perra $\mathrm{JH}$ : Techniques of instrumentation in long fusions to the sacrum. Orthop Clin North Am 25 : 287-299, 1994

17. Sandén $B$, Olerud $C$, Petrén-Mallmin $M$, Johansson $C$, Larsson $S$ : The significance of radiolucent zones surrounding pedicle screws. Definition of screw loosening in spinal instrumentation. J Bone Joint Surg Br 86 : 457-461, 2004

18. Schildhauer TA, McCulloch P, Chapman JR, Mann FA : Anatomic and radiographic considerations for placement of transiliac screws in lumbopelvic fixations. J Spinal Disord Tech 15 : 199-205; discussion 205, 2002

19. Shin JH, Hoh DJ, Kalfas IH : Iliac screw fixation using computer-assisted computer tomographic image guidance: technical note. Neurosurgery 70 : 16-20; discussion 20, 2012

20. Suk SI, Chung ER, Kim JH, Kim SS, Lee JS, Choi WK : Posterior vertebral column resection for severe rigid scoliosis. Spine (Phila Pa 1976) 30 : 1682-1687, 2005

21. Suk SI, Chung ER, Lee SM, Lee JH, Kim SS, Kim JH : Posterior vertebral column resection in fixed lumbosacral deformity. Spine (Phila Pa 1976) 30 : E703-E710, 2005

22. Tsuchiya K, Bridwell KH, Kuklo TR, Lenke LG, Baldus C : Minimum 5-year analysis of L5-S1 fusion using sacropelvic fixation (bilateral S1 and iliac screws) for spinal deformity. Spine (Phila Pa 1976) 31 : 303-308, 2006

23. Wang MY, Berven SH : Lumbar pedicle subtraction osteotomy. Neurosurgery 60 : ONS140-ONS146; discussion ONS146, 2007

24. Williams AL, Gornet MF, Burkus JK : CT evaluation of lumbar interbody fusion: current concepts. AJNR Am J Neuroradiol 26 : 2057-2066, 2005

25. Wu JC, Huang WC, Tsai HW, Ko CC, Wu CL, Tu TH, et al. : Pedicle screw loosening in dynamic stabilization: incidence, risk, and outcome in 126 patients. Neurosurg Focus 31 : E9, 2011 